\title{
Diffusion-Weighted Imaging for the Differential Diagnosis of Disorders Affecting the Hippocampus
}

\author{
A. Förster M. Griebe A. Gass R. Kern M.G. Hennerici K. Szabo \\ Department of Neurology, UniversitätsMedizin Mannheim, University of Heidelberg, Mannheim, Germany
}

\section{Key Words}

Hippocampus · Diffusion-weighted imaging $\cdot$ Stroke $\cdot$

Transient global amnesia $\cdot$ Seizure $\cdot$ Encephalitis

\begin{abstract}
Background: The human hippocampus can be affected in a large variety of very different neurological diseases, of which acute ischemic stroke, transient global amnesia, epilepsy, and limbic encephalitis are the most common. Less frequent etiologies include various infections and encephalopathy of different origins. Clinical presentation notably comprises confusional state, altered vigilance, memory deficits of various extent and seizures. While in hypoxic or hypoglycemic encephalopathy, clinical presentation and surrounding circumstances provide some clues to reach the correct diagnosis, in the above-listed more common disorders, signs and symptoms might overlap, making the differential diagnosis difficult. This review presents recent studies using the diffusion-weighted imaging (DWI) technique in diseases involving the hippocampus. Methods: References for the review were identified through searches of PubMed from 1965 to January 2011. Only papers published in English were reviewed. Full articles were obtained and references were checked for additional material where appropriate. Results: All pathologies affecting the hippocampus are associated
\end{abstract}

with distinct lesion patterns on magnetic resonance imaging, and especially DWI has the ability to demonstrate even minute and transient hippocampal lesions. In acute ischemic stroke in the posterior cerebral artery territory, involvement of the hippocampal formation occurs in four distinct patterns on DWI that can be easily differentiated and correspond to the known vascular anatomy of the hippocampus. In the subacute phase after transient global amnesia (TGA), dot-like hyperintense lesions are regularly found in the lateral aspect of the hippocampus on DWI. The DWI lesions described after prolonged seizures or status epilepticus include unilateral or bilateral hippocampal, thalamic, and cortical lesions of various extent, not restricted to vascular territories. In limbic encephalitis, DWI lesions are only infrequently found and usually affect the hippocampus, uncus and amygdala. Furthermore, in some rare cases DWI lesions of different etiology may coexist. Conclusion: In patients with diseases affecting the hippocampus, DWI appears to be useful in differentiating between underlying pathologies and may facilitate a definite diagnosis conducive to an optimal treatment. With a careful clinical examination, experience with the interpretation of DWI findings and knowledge of associated phenomena, it is indeed possible to differentiate between ischemic, ictal, metabolic, and TGA-associated findings.

Copyright $\odot 2011$ S. Karger AG, Basel

\section{KARGER}

Fax +41613061234 E-Mail karger@karger.ch www.karger.com
(C) 2011 S. Karger AG, Basel

$1015-9770 / 12 / 0332-0104 \$ 38.00 / 0$

Accessible online at:

www.karger.com/ced
Alex Förster, MD

Department of Neurology, UniversitätsMedizin Mannheim, University of Heidelberg

Theodor-Kutzer-Ufer 1-3

DE-68167 Mannheim (Germany)

Tel. +49621383 2885, E-Mail a.foerster@ neuro.ma.uni-heidelberg.de 
Fig. 1. Anatomy and arterial vascularization of the human hippocampus. Drawing of axial section of the left hippocampus (a, b) and coronal section at mid body of the left hippocampus (c, d). The arterial blood vessels shown (b, d) are the PCA (1), the middle hippocampal artery (2), and the posterior hippocampal artery (3) as well as their smaller branches (4). Normal axial $\mathrm{T}_{2}$-weighted (e) and DWI (f) of the hippocampus in a 32-year-old man.
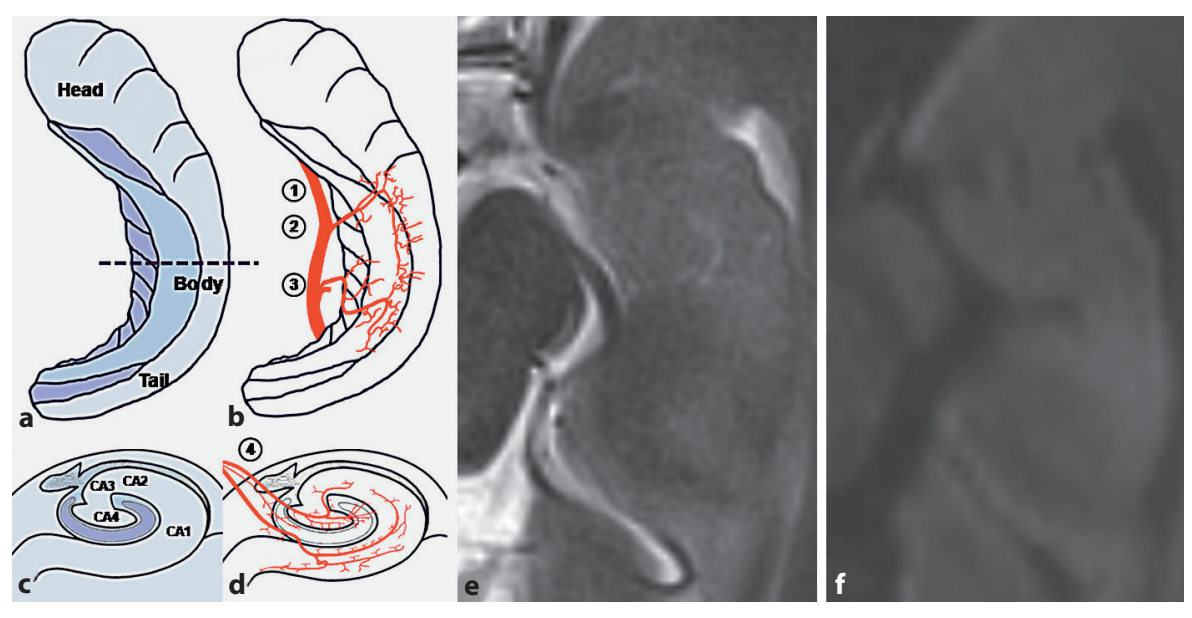

\section{Introduction}

The hippocampus, as part of the limbic system, is a unique and particularly interesting anatomical structure not only because of its critical role in learning [1], memory and emotional behavior [2] but also because of its involvement in endocrinologic stress regulation [3] and its ability for neurogenesis in human adults [4]. Furthermore, the hippocampus can be affected by acute and chronic neurological disorders presenting with more or less characteristic clinical syndromes. These characteristics make the hippocampus one of the most fascinating regions of the human brain for neuroimaging studies.

The hippocampus is part of the limbic lobe, more precisely of the inner limbic gyrus on the medial surface of the cerebral hemispheres, and can be subdivided into three segments: the anterior head, the body and the posterior tail (fig. 1a). On anatomical coronal sections, the hippocampus is usually shown at the mid body, where it comprises two intertwining layers of gray matter: the cornu ammonis (Ammon's horn) and the dentate gyrus. The former consists of four zones of granular cells on microscopic slice preparations: CA1, CA2, CA3, and CA4 (fig. 1c). The hippocampus receives arterial blood mainly from the posterior cerebral artery (PCA) that gives rise to three major arteries or group of arteries: the anterior, middle and posterior hippocampal arteries (fig. 1b, d). The anterior hippocampal artery arises from the spinal artery, a branch of the PCA, the middle and posterior hippocampal arteries either directly from the PCA or from its inferior temporal branches. The contribution of branches of the anterior choroidal artery to the vascular supply of the hippocampal head is highly variable and may be prominent [5].

DWI for the Diagnosis of Disorders

Affecting the Hippocampus
Diffusion-weighted imaging (DWI) has been introduced and established as a routine imaging procedure in acute ischemic stroke in the late 90 s and since then a large number of studies covering numerous different aspects of ischemic stroke have been published. DWI is exquisitely sensitive to demonstrate even minute acute ischemic lesions [6]. Due to their lack of mobility, as a consequence of cytotoxic edema in ischemic tissue water proton light up strongly against the dark background of healthy tissue on DWI, which provides a very high lesionto-background contrast, and is seen as hypointensity on quantitative maps of the apparent diffusion coefficient (ADC). However, this finding is not specific to brain tissue damage after acute ischemic stroke and, as a consequence, DWI studies have identified acute signal changes in brain tissue in several other, quite different neurological disorders [7]. Interestingly, DWI abnormalities located in the hippocampus have recently been described in several acute neurological disorders.

Knowledge of the characteristic features of these - in many cases specific - hippocampal changes may give diagnostic clues and thus aid the clinician in differentiating the underlying pathology. In this article, we aimed to review the medical literature concerning the use of DWI in various neurological disorders affecting the hippocampus.

\section{Search Strategy}

References for the review were indentified through searches of PubMed with the search terms 'hippocamp*' [title] AND ('DWI' [title] OR 'diffusion weighted' [title]) from 1965 to January 2011. Only papers published in English were reviewed. The abstracts of retrieved citations were reviewed and prioritized by relevant con- 
tent. Only case reports with well-documented clinical summaries and relevant information were included in the review. Studies and review articles concerning MRI modalities other than DWI were not included. Full articles were obtained and references were checked for additional material where appropriate.

\section{Acute Ischemic Stroke}

Acute ischemic stroke causes disruption of the cerebral energy metabolism, leading to failure of the $\mathrm{Na}^{+} / \mathrm{K}^{+}$ adenosine triphosphatase pump, a loss of ionic gradients and a net translocation of water from the extracellular to the intracellular compartments. This is now the commonly accepted theory of reduced diffusion in acute stroke that leads to a high signal on DWI and a reduction of ADC. Although acute ischemic stroke is a very common disease, there are only a few case reports on PCA territory infarction involving the hippocampus [8-10], and the medical literature is even more scarce when it comes to MRI investigation of hippocampal infarction $[11,12]$ and its clinical presentation. This may at least partly be explained by the lower rate of posterior circulation strokes, which is about $15 \%$ of all ischemic strokes $[13,14]$. In 2009 , the first comprehensive study was published that focused solely on hippocampal infarction as a subtype of PCA territory infarction and its clinical, neuropsychological and MRI characteristics [15]. On DWI, four typical patterns of hippocampal infarction were recognized and distinguished: involvement of (1) the complete, (2) the lateral, or (3) the dorsal hippocampus (fig. 2), and (4) circumscribed small lesions in the lateral hippocampus. These infarction patterns correspond well with the vascular anatomy of the hippocampus. Most important, additional ischemic lesions in the posterior circulation were found in all patients, suggesting that isolated hippocampal stroke is a rare finding. Clinical signs caused by the lesions outside the hippocampus were the common leading clinical symptoms, whereas evident memory deficits were observed in only one sixth of the patients. However, thorough neuropsychological examination with a comprehensive neuropsychological assessment battery revealed deficits of verbal episodic long-term memory in left and of nonverbal episodic long-term memory in right hippocampal infarction. Bilateral hippocampal infarction, which has been shown to be associated with a pronounced amnesic syndrome [8], is far less frequent and may be considered as an exception to these findings (fig. 3). In the presented case series, only 3 (5\%) patients had bilateral hippocam- pal infarction; 2 of these had an obvious amnesic syndrome, while the 3rd was too severely affected to be examined.

A more recent article focused on patients with PCA territory stroke treated with thrombolysis in an extended time window guided by the DWI/perfusion weighted imaging (PWI) mismatch concept [16]. Interestingly, 3 of these patients had initial ischemic involvement only in the hippocampus - while on follow-up MRI, extrahippocampal structures were affected in all the cases. As these patients were examined earlier than those in the first study (maximum $6 \mathrm{~h}$ vs. maximum $72 \mathrm{~h}$ ), this phenomenon might be explained by the vulnerability of the hippocampus to hypoxia known from experimental studies [17].

\section{Transient Global Amnesia}

Transient global amnesia (TGA) is a neurological disorder characterized by a sudden onset of antero- and retrograde amnesia, and complete recovery from this cognitive disturbance within $24 \mathrm{~h}$. Since the first description in the 1950s $[18,19]$ neurologists were fascinated by the unique clinical presentation of this relatively rare neurological disease (the incidence has been estimated at $5-10 / 100,000 /$ year). The underlying etiology is unknown, but cortical spreading depression, ischemic stroke and venous congestion have been proposed as possible pathomechanisms.

In the late 1990s, the first case reports on TGA patients with circumscribed regions of altered diffusion on DWI appeared in the medical literature. Strupp et al. [20] reported a case series of TGA patients with widespread unilateral or bilateral signal abnormalities in the hippocampus on DWI. This finding was interpreted as evidence for spreading depression. Other authors reported on TGA patients with multiple DWI lesions in the PCA territory (hippocampus, thalamus, splenium, occipital lobe) [21,22] or only small hippocampal DWI lesions [23], but the question whether these DWI lesions were a typical finding in TGA was not satisfactorily answered, especially so as other authors failed to find similar results [24-26]. A large series of TGA patients systematically studied with serial MRI examinations was not published until 2004 [27]. While no DWI or $\mathrm{T}_{2}$ changes were detected in the acute phase of the disease, serial DWI showed very small, dot-like DWI lesions with a diameter of approximately $1-2 \mathrm{~mm}$ in the lateral aspect of the hippocampus that became visible after $48 \mathrm{~h}$ (see 

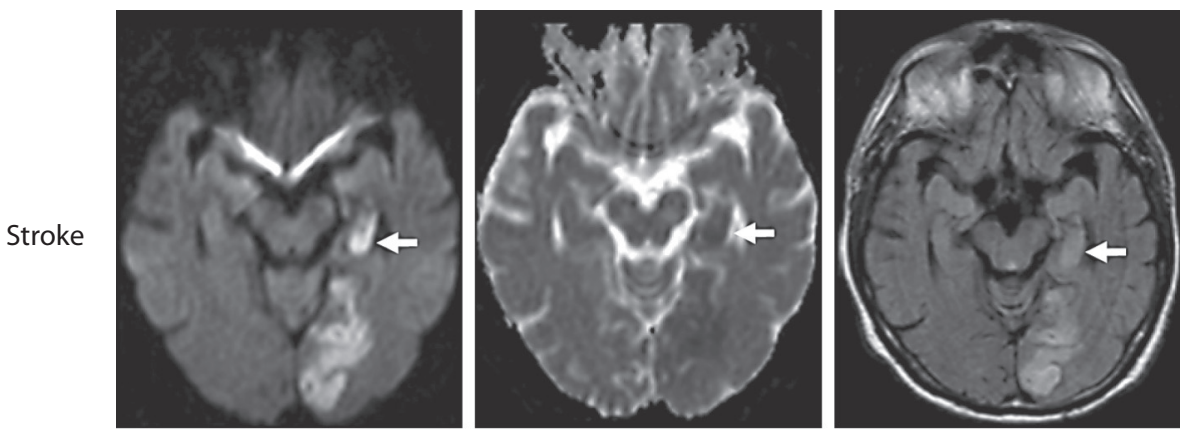

Seizure
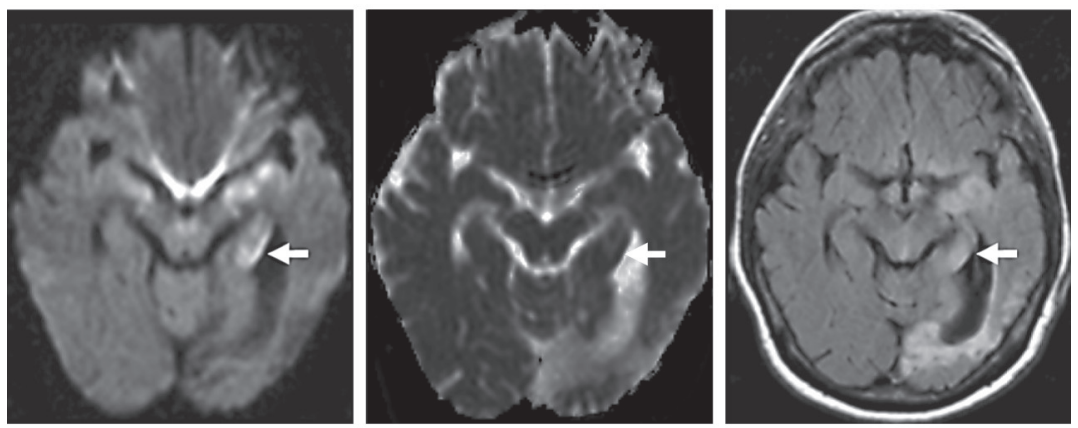

TGA
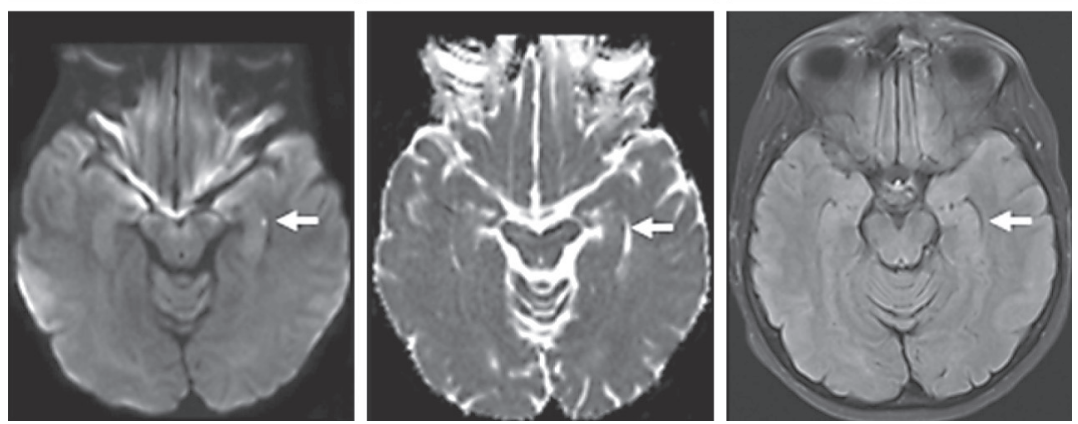

DWI high

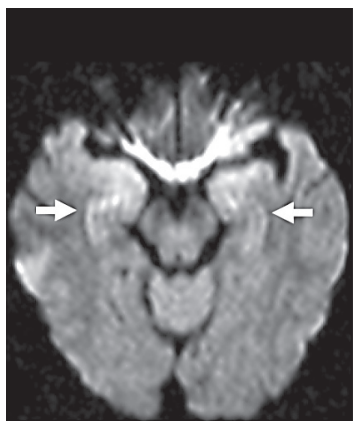

ADC normal/increased

T2-weighted FLAIR high

Fig. 2. Differential diagnosis for hippocampal lesions with a high diffusion signal. $\mathrm{LE}=$ Limbic encephalitis; TGA = transient global amnesia.
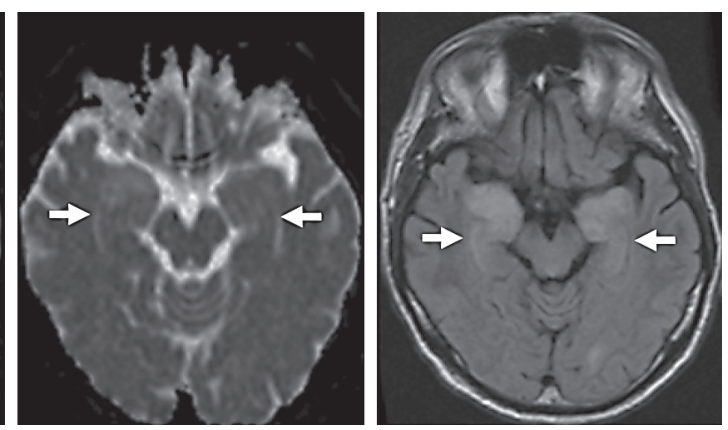

fig. 2 for an example). In most cases, the observed lesions appeared as a small area with reduced signal on ADC maps and a high signal on $\mathrm{T}_{2}$-weighted images. Time between onset and MRI seems to be crucial for detecting DWI lesions in TGA as about $70-80 \%$ of the patients displayed punctate hippocampal DWI changes after 24$48 \mathrm{~h}$, but only about $6 \%$ of patients did so in the acute phase. After reevaluation, the lesions were also visible on the initial DW MRI in about one third of TGA patients. This important finding may also explain the lack of 


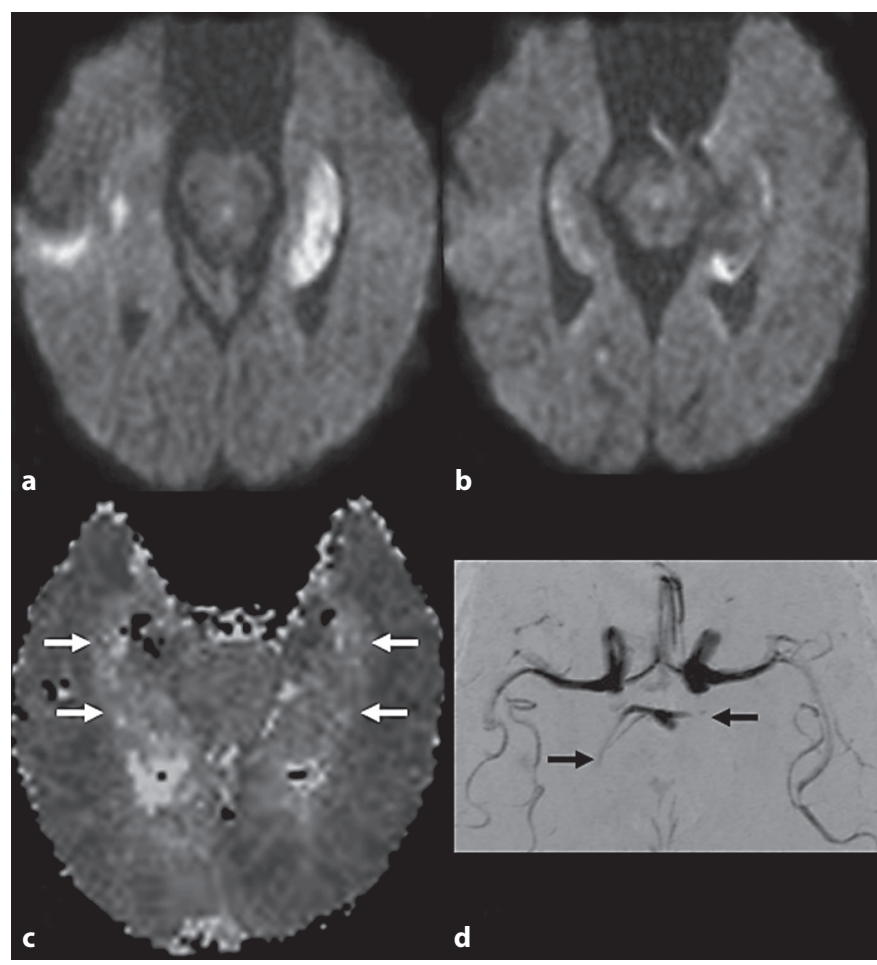

Fig. 3. Case report 1: bilateral hippocampal stroke. Example of an 81-year-old man with acute gait disorder and sensorimotor hemiparesis as well as a prominent anterograde amnestic syndrome: DWI $(\mathbf{a}, \mathbf{b})$ shows bilaterally located acute ischemic lesions in the hippocampus. Delay of contrast agent arrival on the time-to-peak map (white arrows) of the perfusion image (c) is explained by occlusion of both PCAs (black arrows) on MRA (d).

DWI lesions in previous studies that only focused upon MRI in the acute phase. Other groups have confirmed these findings since then [28]. Subsequent studies have refined and endorsed our knowledge about the typical DWI abnormalities in TGA, describing the selective affection of the CA1 sector of the hippocampus [29, 30], association of lesion location and neuropsychological deficits in the subacute phase [29], evolution of the hippocampal lesion over time [31], or the optimal diffusionweighted imaging protocol [32]. In light of this knowledge, the first case reports mentioned above $[21,22]$ may be regarded as rather unusual examples. Although the described typical clinical presentation leaves no doubt about the clinical diagnosis, both cases might represent the infrequent coincidence of acute ischemic stroke in the PCA territory and TGA. For a similar example see figure 4. Although the lesion pattern in TGA is arguably

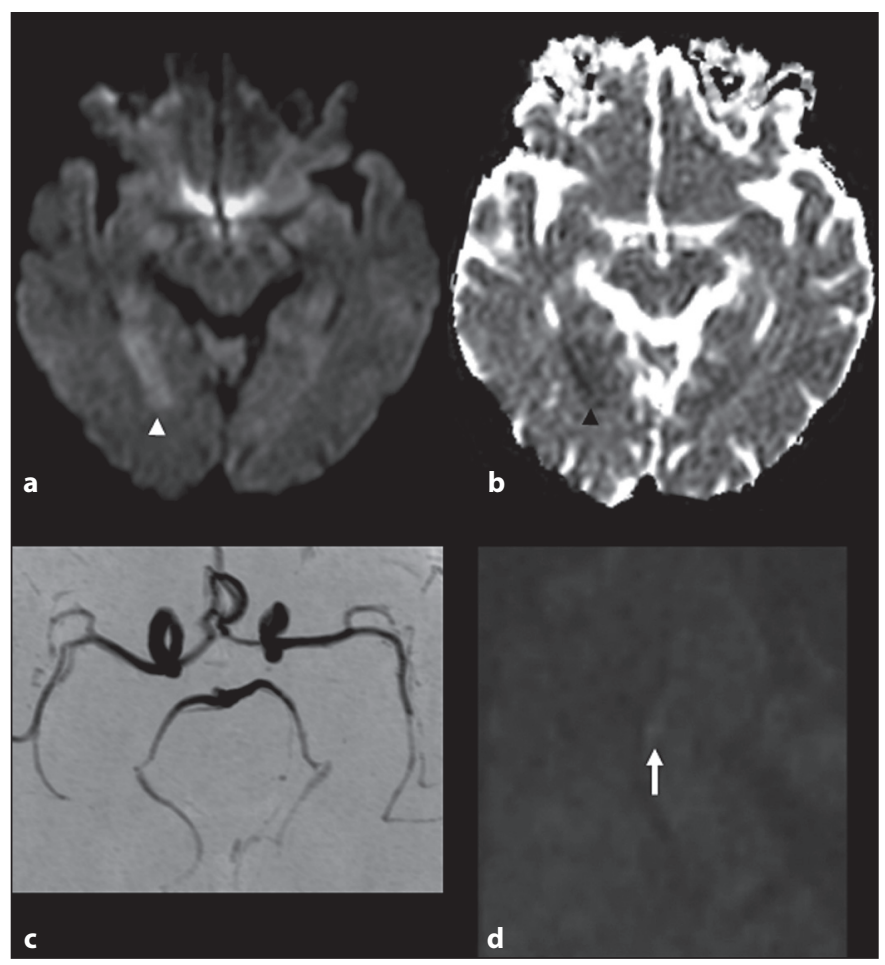

Fig. 4. Case report 2: PCA stroke and TGA. Example of a 59-yearold teacher with an acute gait disorder, right homonymous hemianopia, and word-finding difficulties occurring at work: initial DWI (a) and ADC (b) show an acute ischemic lesion in the right PCA territory (arrowhead). MRA is unremarkable (c). In the clinical course, the patient - who was extremely embarrassed by stroke onset - developed a typical TGA episode with antero- and retrograde amnesia from which she recovered within $15 \mathrm{~h}$. DWI (d) showed a new small lesion in the lateral aspect of the right hippocampus (arrow) on follow-up.

comparable to hippocampal stroke pattern 4 as described above, it is still difficult to consider these lesions as typical ischemic lesions, mostly as these stroke patients do not exhibit TGA-like features.

The underlying pathology of the DWI changes associated with TGA is still unclear. While delayed ischemic or hypoxic mechanisms have been proposed, it remains difficult to perceive these lesions as typical vascular ischemic changes. In agreement with this position, Toledo et al. [33] did not find any perfusion abnormalities on PWI in TGA patients during the acute or subacute phase nor did they detect vascular pathologies on MR angiography. Comparison of TGA patients and healthy controls did not reveal any significant differences with regard to vascular risk factors, concomitant chronic white matter lesions, degree of atherosclerosis, or cardiac abnormalities, and the same held true for TGA pa- 
tients with and without typical hippocampal DWI lesions [34]. However, as these DWI abnormalities may be regarded as pathognomonic of TGA, it may be reasonable to include them as an alternative criterion in addition to Hodges and Warlow's [35] criteria for definite TGA. Especially in cases with uncertain onset or less characteristic presentation, this might be useful to support the diagnosis.

\section{Seizures and Status Epilepticus}

The first reports on hippocampal DWI changes in patients with seizures were published at the beginning of this century. Kim et al. [36] presented a case series of patients with generalized tonic-clonic seizures or status epilepticus and demonstrated increased signal intensity on DWI in the hippocampus in 3 patients and in the parahippocampal gyrus in 1 patient [36]. Similarly, increased signal intensity in the parahippocampal gyrus was found on DWI in 2 patients with intractable temporal lobe epilepsy and single short seizures or status epilepticus [37]. Another case report described an increased DWI signal in the hippocampus, temporoparietal cortex and cerebellum, and hyperperfusion in the ipsilateral hemisphere in a patient with focal convulsive status epilepticus [38]. In children with new-onset psychomotor seizures, diffusion abnormalities were found in the whole hippocampus. Interestingly, all patients developed hippocampal atrophy as detected on follow-up MRI and continued to have occasional seizures or even developed intractable complex partial epilepsy [39].

In 2005 , a case series of patients with symptomatic complex partial status epilepticus and diffusion abnormalities was published that showed hippocampal hyperintensity in 8 out of 10 patients. Interestingly, the most frequent location of these findings was the hippocampal formation together with the pulvinar region of the thalamus, whereas isolated involvement of the hippocampal formation or of cortical regions occurred less often. Matching areas of decreased ADC signal were found in all cases as well as slight focal swelling accompanied by hyperintensity on $\mathrm{T}_{2}$-weighted images. For examples of postictal DWI changes in the hippocampus, see figure 2. Furthermore, a closely matching area of hyperperfusion was found in all patients most likely representing a compensatory mechanism in response to ictal overactivation. On follow-up MRI, slight DWI hyperintensity was still noted in 4 patients, whereas in the remaining patients, DWI abnormalities resolved gradually and had

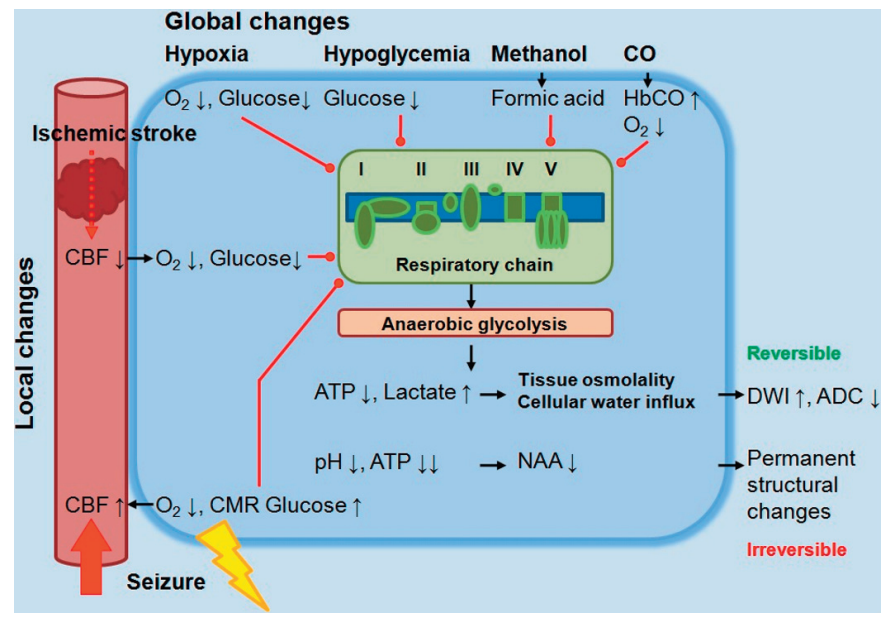

Fig. 5. Pathophysiological consequences in local (ischemic stroke, seizures) and global (hypoxia, hypoglycemia, methanol and carbon monoxide poisoning) conditions impairing neuronal energy metabolism affecting diffusion. $\mathrm{CBF}=$ Cerebral blood flow; $\mathrm{O}_{2}=$ oxygen; $\mathrm{CMR}=$ cerebral metabolic rate; $\mathrm{HbCO}=$ carbon monoxide hemoglobin; ATP = adenosine triphosphate; NAA = N-acetylaspartate.

normalized on follow-up MRI performed after 2 weeks or later [40]. In contrast to these findings, Bonaventura et al. [41] detected hippocampal diffusion changes in only 2 out of 10 patients with complex partial status epilepticus, although DWI revealed signal alterations in all patients. Similarly, these signal changes had resolved completely on follow-up MRI. Another case series of patients with symptomatic seizures or status epilepticus showed hippocampal diffusion abnormalities in all 12 patients and bilateral lesions in 5 of these. In most patients, the whole hippocampus was affected; only in a subset of patients was altered diffusion limited to the head and body or body and tail. Cortical involvement was found in about half of the patients, all of whom suffered from encephalitis or systemic lupus erythematosus [42]. Not surprisingly, the hippocampal diffusion signal changes after seizures or status epilepticus have been demonstrated to be closely related to ipsilateral EEG abnormalities [40-44] or to the side of clinical seizure onset [44].

The pathogenesis of these DWI abnormalities in seizures and status epilepticus is believed to be due to compromised energy metabolism as prolonged ictal activity is known to increase glucose utilization, the increase of which is not adequately matched by the enhanced blood flow. Consequently, this imbalance of supply and de- 


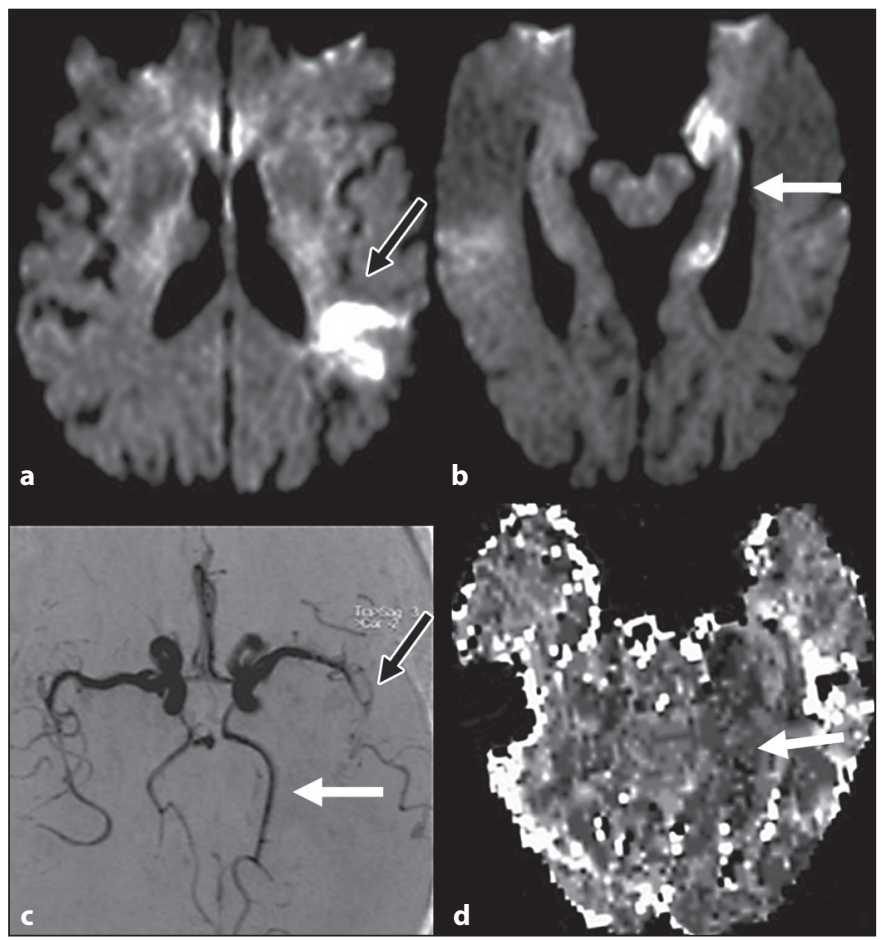

Fig. 6. Case report 3: postictal DWI findings. Example of a 76 -year-old woman who was admitted to the Stroke Unit due to acute onset of sensory aphasia from which she recovered within 1 day. On day 3, she developed sudden confusion with disorientation, stereotypical repetitive actions and amnesia. On DWI, an acute ischemic lesion in the left middle cerebral artery (MCA) territory (a) and a vascular pathology in the left MCA on MRA (c) were seen (black arrows). Additionally, a hyperintense signal change on DWI (b) was noted in the left hippocampus associated with signs of hyperperfusion in the PCA territory on MRA (c) and on time-to-peak maps on PWI (d, white arrows). The left PCA territory showed focal hyperperfusion, indicating that not ischemia but ictal activity, that was confirmed subsequently by a pathological EEG, was responsible for the morphological changes in the hippocampus.

mand may lead to cytotoxic cell swelling and vasogenic edema resulting in restricted diffusion detected on DWI and ADC (fig. 5). In contrast to acute ischemia, where DWI reveals diffusion abnormalities within $30 \mathrm{~min}$ and before any $\mathrm{T}_{2}$ signal changes appear, in ongoing status epilepticus, DWI and $\mathrm{T}_{2}$ signal changes may occur simultaneously. This finding probably indicates a different pathophysiology, with cytotoxic edema induced by the ictal activity preceding a manifest energy deficiency. In turn, this might explain the frequently observed reversibility of DWI changes in patients with seizures or status epilepticus [40,42]. As shown in figure 6, the coincidence of DWI lesions caused by ischemic stroke and seizures is a challenging constellation of findings, but with a careful clinical examination and experience with ictal phenomena on MRI, it is indeed possible to differentiate between ischemic and ictal or metabolic lesions.

\section{Infections and Inflammatory Diseases}

The most common inflammatory disease affecting the hippocampus is limbic encephalitis that occurs in three major forms: (1) a paraneoplastic subtype which is related to onconeural antibodies in patients with malignant tumors, (2) a nonparaneoplastic subtype that is mainly caused by voltage-gated potassium channel antibodies and (3) an infectious subtype caused by herpesvirus. The clinical presentation is characterized by subacute onset of seizures, memory deficits, confusional state, altered vigilance and psychiatric symptoms.

In paraneoplastic and nonparaneoplastic limbic encephalitis, only a few case reports $[45,46]$ and a single case series [47] detected hippocampal DWI abnormalities, and it remained unclear whether these represented cytotoxic changes in water distribution or mainly a $\mathrm{T}_{2}$ shine-through effect. Figure 2 shows typical MRI findings in a patient with nonparaneoplastic limbic encephalitis. Limbic encephalitis has also been increasingly recognized as a typical finding in immunocompromised patients, in particular after allogeneic hematopoietic stem cell transplantation in hematologic malignancies. The clinical presentation is not different to that observed in paraneoplastic or nonparaneoplastic limbic encephalitis. It is caused by human herpes virus-6, an ubiquitous neurotropic DNA virus known to cause exanthema subitum and sometimes febrile seizures in childhood and to persist lifelong in about $90 \%$ of adults. The first case reports on hippocampal DWI hyperintensities in human herpes virus-6 encephalitis were published in 2006 [48, 49]. While in the first report the ADC was reduced in only 1 patient and was considered by the authors to be a consequence of recent seizures, the authors of the second study ascribed a substantial part of the acute pathology of human herpes virus- 6 encephalitis to cytotoxic edema. In a more comprehensive case series, Seeley et al. [50] described the clinical and MRI findings in 8 patients with human herpes virus- 6 encephalitis. All patients demonstrated hyperintensities within the uncus, amygdala, and the hippocampus, extending to the entorhinal cortex and subiculum on DWI. However, ADC maps (available in 4 patients) suggested impaired diffusion in only 1 patient 
and a $\mathrm{T}_{2}$ shine-through effect in the remaining cases. In comparison to the widespread DWI abnormalities in herpes simplex virus encephalitis including the hippocampal formation and amygdala but also other brain regions, such as the insular, frontal, temporal or parietooccipital cortices, increased DWI signal intensity is limited to the hippocampus and amygdala in patients with human herpes virus- 6 encephalitis. With regard to the lesion characteristics during the clinical course with an increased DWI signal and reduced ADC values in the early and middle phase (0-30 days after onset) and disappearance of these changes in the late phase (more than 30 days after onset), there were no significant differences between the two conditions [51].

Other infections associated with changes in hippocampal DWI signals are very rare. Poon et al. [52] reported on a patient with a cerebellar variant of CreutzfeldtJakob disease, who had increased DWI signal in both hippocampi in addition to extensive signal changes in the basal ganglia, thalamus and cerebellum. Although the hippocampal formation is frequently affected histopathologically in patients with Creutzfeldt-Jakob disease, this is a rather unusual finding. Another form of infectious encephalitis that occasionally may be the cause of hippocampal DWI abnormalities is Japanese encephalitis. Again, hippocampal DWI changes were accompanied by increased DWI signal in other brain regions (both thala$\mathrm{mi}$ ) in the reported case [53].

\section{Anoxic Encephalopathy and Encephalopathies of Other Etiology}

Diffusion abnormalities in different brain regions may also be present in patients with anoxic encephalopathy; they can be subdivided into hypoxic-ischemic encephalopathy (e.g. caused by cardiac arrest), hypoxic hypoxia (e.g. caused by suicide by hanging), histotoxic hypoxia (e.g. caused by carbon monoxide poisoning) and anemic hypoxia according to its pathophysiology.

In hypoxic-ischemic encephalopathy, DWI demonstrates widespread signal abnormalities in the basal ganglia, caudate nucleus, striate nucleus and thalamus, followed by the cortex and subcortical white matter, cerebellum and hippocampus. Wijdicks et al. [54] followed patients who remained comatose after cardiopulmonary resuscitation for a period of 12 months. While all patients who underwent MRI except 1 showed hippocampal signal abnormalities on fluid-attenuated inversion recovery (FLAIR) images, only 1 patient had increased signal intensity in the hippocampus on DWI. Only those patients without or minimal signal changes on MRI awakened later. In a case report of a 66-year-old man who was resuscitated after cardiorespiratory arrest, the authors found a delayed manifestation of DWI abnormalities in the hippocampus, corpus callosum and deep white matter, whereas other brain structures, such as the cerebellum, cerebral cortex, caudate nucleus and putamen, were affected earlier [55]. In a more differentiated approach, Mlynash et al. [56] qualitatively and quantitatively assessed predefined brain regions in comatose survivors of cardiac arrest and compared the results to normal controls. Moderate to severe DWI signal changes in the hippocampal formation were significantly more often observed in patients with a poor outcome. Interestingly, while patients with poor outcome exhibited a nonsignificant decrease in ADC values compared to patients with a good outcome; the latter showed increased ADC values in the hippocampus compared to healthy control subjects and this finding was interpreted as mild vasogenic edema caused by transient increased blood-brain barrier permeability. With regard to hippocampal abnormalities on DWI in patients with hypoxic hypoxia or histotoxic hypoxia, only a few case reports have been published until today. In patients with carbon monoxide poisoning, DWI abnormalities in the hippocampus may be the only finding or may occur in combination with DWI signal changes in other brain regions, such as the globus pallidus, occipital and temporal lobes and cerebellum [57]. After attempted suicidal hanging, hippocampal DWI lesions can be observed in addition to widespread lesions in the striate nucleus, thalamus, and occipital and parietal cortices [57]. A differentiation of pathophysiology in anoxic encephalopathy based on DWI findings is not supported by the literature.

Hypoglycemic coma can be associated with extensive DWI hyperintensities notably involving the cerebral cortex, the hippocampus and the basal ganglia. The first case report of DWI findings in a patient with hypoglycemic coma was published in 2001 and demonstrated symmetrical lesions in the hippocampus, caudate nucleus, putamen and temporal cortex [58]. In another case report from 2006, hippocampal lesions were relatively small, and the authors concluded that the hippocampus might be more resistant to prolonged hypoglycemia than to global hypoxia [59]. In contrast to this finding, Lim et al. [60] found hippocampal signal abnormalities on DWI in all patients with severe hypoglycemia who had consumed an illegal sexual enhancement product 
Table 1. Common clinical constellations and DWI findings in different neurological disorders affecting the hippocampus

\begin{tabular}{lll}
\hline Etiology & Clinical presentation & DWI findings \\
\hline Stroke & $\begin{array}{l}\text { Sudden onset of homonymous quadrantanopia or hemianopia, } \\
\text { hemivisual neglect, verbal dyslexia } \\
\text { Obvious memory deficits (if left or both hippocampi involved) } \\
\text { Sensory loss, dysesthesias, hemiparesis, choreoathetosis, spasms } \\
\text { of hand }\end{array}$ & $\begin{array}{l}\text { Patterns according to vascular pathology: } \\
\text { (1) complete, (2) dorsal, (3) lateral, (4) small } \\
\text { circumscribed lesion } \\
\text { Additional lesions in the PCA territory }\end{array}$ \\
\hline TGA & $\begin{array}{l}\text { Sudden onset of anterograde amnesia } \\
\text { Complete resolution within 24 h }\end{array}$ & $\begin{array}{l}\text { Small circumscribed lesions of 1-2 mm in } \\
\text { diameter }\end{array}$ \\
& $\begin{array}{l}\text { No disturbance of consciousness } \\
\text { No other neurological deficit or features of ictal activity }\end{array}$ & $\begin{array}{l}\text { Lateral part of the hippocampus, CA-1 region } \\
\text { Delayed occurrence }\end{array}$ \\
\hline Seizure & $\begin{array}{l}\text { Nonspecific symptoms (altered vigilance, confusion, } \\
\text { alterations in mental status, aphasia, hemiparesis) }\end{array}$ & $\begin{array}{l}\text { Involvement of the lateral hippocampus } \\
\text { Additional hyperintensities in the pulvinar or } \\
\text { cortex }\end{array}$ \\
& $\begin{array}{l}\text { Single seizure (febrile, psychomotor, generalized tonic-clonic) } \\
\text { Repetitive seizures and status epileticus (nonconvulsive, focal } \\
\text { convulsive, complex partial, generalized tonic-clonic) }\end{array}$ & $\begin{array}{l}\text { Uncus, amygdale, hippocampus } \\
\text { Extending to the entorhinal cortex and } \\
\text { subiculum }\end{array}$ \\
\hline $\begin{array}{l}\text { Limbic } \\
\text { encephalitis }\end{array}$ & $\begin{array}{l}\text { Subacute onset of altered vigilance, confusion } \\
\text { Memory deficits and psychiatric symptoms }\end{array}$ &
\end{tabular}

TGA = Transient global amnesia; DWI = diffusion-weighted imaging.

adulterated with glibenclamide, an oral antidiabetic drug. Further lesions were detected in the parietal, temporal, occipital and frontal cortices, and, in many cases, the splenium of the corpus callosum whereas lesions of the internal capsule and basal ganglia were observed in only 1 patient. About one third of patients in a larger series of patients with hypoglycemic coma exhibited hippocampal DWI hyperintensities, and in a subset of patients, these signal changes had completely disappeared on follow-up MRI [61]. While some authors reported hippocampal involvement to be a negative predictor of clinical outcome, this was not the case in the series described by Kang et al. [61]. Several pathomechanisms have been suggested for diffusion abnormalities in hypoglycemic encephalopathy: (1) breakdown of energy metabolism, (2) excitotoxic edema caused by an increased extracellular glutamate concentration, and (3) unequal cerebral blood flow impairment by focal loss of autoregulation.

Other encephalopathies, such as hyperammonemic encephalopathy [62] and intoxications with glufosinate, a herbicide [63], or methanol [64], are rarely accompanied by changes in DWI signal in the hippocampus.

\section{Conclusions}

The hippocampus can be affected in different neurological diseases, such as global or focal hypoxia, TGA, epilepsy, infections and autoimmune conditions, and this may result in hyperintense DWI signal. Although all of these pathologies are associated with a more or less characteristic clinical presentation, signs and symptoms may overlap (table 1) and differential diagnosis based on clinical presentation alone may be challenging. However, on the basis of distinct lesion patterns (fig. 3), DWI can provide additional diagnostic information that may facilitate and support the final diagnosis, especially if clinical symptoms are inconclusive.

In acute ischemic stroke in the PCA territory, involvement of the hippocampal formation as a result of cytotoxic edema occurs in four distinct patterns that can be easily differentiated and correspond to the known vascular anatomy of the hippocampus. Furthermore, additional lesions involving other cerebral structures supplied by the PCA, such as the thalamus, the splenium, or the occipital lobe, can almost always be found in completed hippocampal stroke. Ischemic lesions of the hippocampus may be accompanied by a persistent abnormality of the PCA and corresponding hypoperfusion. While unilateral hippocampal involvement in stroke 
may cause no or very subtle memory disturbance, bilateral hippocampal ischemia results in pronounced memory disturbance.

Meanwhile, characteristic DWI lesions are widely accepted as a typical finding in patients in the subacute phase after TGA. With a delay of $24-48 \mathrm{~h}$, dot-like hyperintense lesions are regularly found in the lateral aspect of the hippocampus; they may be single or multiple, uni- or bilateral. These lesions have been confirmed by many groups, and while this finding anatomically links the disorder to the hippocampus, the exact etiology still remains uncertain.

The DWI lesions described after prolonged seizures or status epilepticus differ in the underlying pathomechanism and the resulting lesion patterns. Typical lesion patterns include unilateral or bilateral hippocampal, thalamic, and cortical lesions of various extent, not restricted to vascular territories and frequently accompanied by extensive hyperperfusion. Usually, the whole lateral aspect of the hippocampus or the whole hippocampus is affected. These findings possibly reflect the specific vulnerability of individual brain tissues such as the hippocampus on the one hand and the specific localization of ictal activity on the other hand. Hyperintense changes in DWI signal in the hippocampus accompanied by signs of hyperperfusion may provide a diagnostic clue to the underlying ictal pathology of prolonged confusional syndromes, especially in the elderly or in patients with other primary central nervous system pathologies.
DWI lesions are infrequently found in limbic encephalitis, and usually they affect the hippocampus, uncus and amygdala. Whether these represent a characteristic finding in a specific stage of the pathophysiology or rather a $T_{2}$ shine-through effect remains unclear. Furthermore, as seizures are a typical symptom, postictal and inflammatory DWI changes may indistinguishably overlap.

In contrast to the above-described etiologies, extensive DWI abnormalities in both hemispheres and independent of vascular territories may be detected in global hypoxia. In other encephalopathies induced by agents that compromise the neuronal energy metabolism via the respiratory chain by very different mechanisms, such as hypoglycemia, carbon monoxide poisoning, or methanol intoxication (fig. 5), lesion patterns may be similar to those observed in global hypoxia.

In diseases affecting the hippocampus, besides the clinical presentation, other investigations including EEG, Doppler/duplex ultrasound, laboratory tests, and MRI, in particular DWI, appear to be useful to differentiate between underlying pathologies and may facilitate a definite diagnosis conducive to an optimal treatment. In some - admittedly rare - cases, DWI lesions of different etiology may coexist. With a careful clinical examination and experience with DWI hyperintense phenomena on MRI, it is indeed possible to differentiate between ischemic, ictal, metabolic, and TGA-associated findings.

\section{References}

1 Chong H, Riis JL, McGinnis SM, Williams DM, Holcomb PJ, Daffner KR: To ignore or explore: top-down modulation of novelty processing. J Cogn Neurosci 2008;20:120134.

-2 Moscovitch M, Rosenbaum RS, Gilboa A, Addis DR, Westmacott R, Grady C, McAndrews MP, Levine B, Black S, Winocur G, Nadel L: Functional neuroanatomy of remote episodic, semantic and spatial memory: a unified account based on multiple trace theory. J Anat 2005;207:35-66.

3 Herman JP, Ostrander MM, Mueller NK, Figueiredo H: Limbic system mechanisms of stress regulation: hypothalamo-pituitaryadrenocortical axis. Prog Neuropsychopharmacol Biol Psychiatry 2005;29:1201-1213.

$\checkmark 4$ Bruel-Jungerman E, Rampon C, Laroche S: Adult hippocampal neurogenesis, synaptic plasticity and memory: facts and hypotheses. Rev Neurosci 2007;18:93-114.
5 Duvernoy HM: The human hippocampus Berlin, Springer, 2004.

6 Gass A, Ay H, Szabo K, Koroshetz WJ: Diffusion-weighted MRI for the 'small stuff': the details of acute cerebral ischaemia. Lancet Neurol 2004;3:39-45.

7 Gass A, Niendorf T, Hirsch JG: Acute and chronic changes of the apparent diffusion coefficient in neurological disorders - biophysical mechanisms and possible underlying histopathology. J Neurol Sci 2001; 186(suppl 1):S15-S23.

$\checkmark 8$ Victor M, Angevine JB, Mancall EL, Fisher CM: Memory loss with lesions of hippocampal formation. Report of a case with some remarks on the anatomical basis of memory. Arch Neurol 1961;5:244-263.

-9 Mohr JP, Leicester J, Stoddard LT, Sidman M: Right hemianopia with memory and color deficits in circumscribed left posterior cerebral artery territory infarction. Neurology 1971;21:1104-1113.
10 Caplan LR, Hedley-Whyte T: Cuing and memory dysfunction in alexia without agraphia. A case report. Brain 1974;97:251-262.

11 Ott BR, Saver JL: Unilateral amnesic stroke. Six new cases and a review of the literature. Stroke 1993;24:1033-1042.

12 Takahashi S, Higano S, Kurihara N, Mugikura S, Sakamoto K, Nomura H, Ikeda H: Correlation of lesions in the hippocampal region noted on MR images with clinical features. Eur Radiol 1997;7:281-286.

$\checkmark 13$ Lee E, Kang DW, Kwon SU, Kim JS: Posterior cerebral artery infarction: diffusion-weighted MRI analysis of 205 patients. Cerebrovasc Dis 2009;28:298-305.

-14 Tao WD, Kong FY, Hao ZL, Lin S, Wang DR, Wu B, Liu M: One-year case fatality and disability after posterior circulation infarction in a Chinese hospital-based stroke study. Cerebrovasc Dis 2010;29:376-381. 
15 Szabo K, Förster A, Jäger T, Kern R, Griebe M, Hennerici MG, Gass A: Hippocampal lesion patterns in acute posterior cerebral artery stroke: clinical and MRI findings. Stroke 2009;40:2042-2045.

-16 Förster A, Gass A, Kern R, Wolf ME, Hennerici MG, Szabo K: MR imaging-guided intravenous thrombolysis in posterior cerebral artery stroke. AJNR Am J Neuroradiol 2011; 32:419-421.

17 Brierly JB, Graham DI: Hypoxia and vascular disorders of the central nervous system; in Adams JH, Corsellis JAN, Duchen LW (eds): Greenfield's Neuropathology. New York, Wiley, 1984, pp 125-207.

18 Guyotat M, Courjon J: Les ictus amnésiques. J Méd Lyon 1956;37:697-701.

19 Bender MB: Syndrome of isolated episode of confusion with amnesia. J Hillside Hosp 1956;5:212-215.

-20 Strupp M, Bruning R, Wu RH, Deimling M, Reiser M, Brandt T: Diffusion-weighted MRI in transient global amnesia: elevated signal intensity in the left mesial temporal lobe in 7 of 10 patients. Ann Neurol 1998;43:164-170.

-21 Woolfenden AR, O’Brien MW, Schwartzberg RE, Norbash AM, Tong DC: Diffusionweighted MRI in transient global amnesia precipitated by cerebral angiography. Stroke 1997;28:2311-2314.

-22 Ay H, Furie KL, Yamada K, Koroshetz WJ: Diffusion-weighted MRI characterizes the ischemic lesion in transient global amnesia. Neurology 1998;51:901-903.

-23 Matsui M, Imamura T, Sakamoto S, Ishii K, Kazui H, Mori E: Transient global amnesia: increased signal intensity in the right hippocampus on diffusion-weighted magnetic resonance imaging. Neuroradiology 2002;44: 235-238.

-24 Budson AE, Schlaug G, Briemberg HR: Perfusion- and diffusion-weighted magnetic resonance imaging in transient global amnesia. Neurology 1999;53:239-240.

25 Gass A, Gaa J, Hirsch J, Schwartz A, Hennerici MG: Lack of evidence of acute ischemic tissue change in transient global amnesia on single-shot echo-planar diffusion-weighted MRI. Stroke 1999;30:2070-2072.

-26 Huber R, Aschoff AJ, Ludolph AC, Riepe MW: Transient global amnesia. Evidence against vascular ischemic etiology from diffusion-weighted imaging. J Neurol 2002;249: 1520-1524.

-27 Sedlaczek O, Hirsch JG, Grips E, Peters CN, Gass A, Wohrle J, Hennerici M: Detection of delayed focal MR changes in the lateral hippocampus in transient global amnesia. Neurology 2004;62:2165-2170.

-28 Cianfoni A, Tartaglione T, Gaudino S, Pilato F, Saturno E, Tonali PA, Di L, V: Hippocampal magnetic resonance imaging abnormalities in transient global amnesia. Arch Neurol 2005;62:1468-1469.
29 Bartsch T, Alfke K, Stingele R, Rohr A, Freitag-Wolf S, Jansen O, Deuschl G: Selective affection of hippocampal CA-1 neurons in patients with transient global amnesia without long-term sequelae. Brain 2006;129: 2874-2884.

30 Lee HY, Kim JH, Weon YC, Lee JS, Kim SY, Youn SW, Kim SH: Diffusion-weighted imaging in transient global amnesia exposes the CA1 region of the hippocampus. Neuroradiology 2007;49:481-487.

-31 Bartsch T, Alfke K, Deuschl G, Jansen O: Evolution of hippocampal CA-1 diffusion lesions in transient global amnesia. Ann Neurol 2007;62:475-480.

32 Weon YC, Kim JH, Lee JS, Kim SY: Optima diffusion-weighted imaging protocol for lesion detection in transient global amnesia. AJNR Am J Neuroradiol 2008;29:1324-1328.

33 Toledo M, Pujadas F, Grive E, Alvarez-Sabin J, Quintana M, Rovira A: Lack of evidence for arterial ischemia in transient global amnesia. Stroke 2008;39:476-479.

34 Enzinger C, Thimary F, Kapeller P, Ropele S, Schmidt R, Ebner F, Fazekas F: Transient global amnesia: diffusion-weighted imaging lesions and cerebrovascular disease. Stroke 2008;39:2219-2225.

35 Hodges JR, Warlow CP: Syndromes of transient amnesia: towards a classification. A study of 153 cases. J Neurol Neurosurg Psychiatry 1990;53:834-843.

36 Kim JA, Chung JI, Yoon PH, Kim DI, Chung TS, Kim EJ, Jeong EK: Transient MR signal changes in patients with generalized tonicoclonic seizure or status epilepticus: periictal diffusion-weighted imaging. AJNR Am J Neuroradiol 2001;22:1149-1160.

37 Diehl B, Najm I, Ruggieri P, Tkach J, Mohamed A, Morris H, Wyllie E, Fisher E, Duda J, Lieber M, Bingaman W, Luders HO: Postictal diffusion-weighted imaging for the localization of focal epileptic areas in temporal lobe epilepsy. Epilepsia 2001;42:21-28.

38 El Koussy M, Mathis J, Lovblad KO, Stepper F, Kiefer C, Schroth G: Focal status epilepticus: follow-up by perfusion- and diffusion MRI. Eur Radiol 2002;12:568-574.

-39 Farina L, Bergqvist C, Zimmerman RA, Haselgrove J, Hunter JV, Bilaniuk LT: Acute diffusion abnormalities in the hippocampus of children with new-onset seizures: the development of mesial temporal sclerosis. Neuroradiology 2004;46:251-257.

40 Szabo K, Poepel A, Pohlmann-Eden B, Hirsch J, Back T, Sedlaczek O, Hennerici M, Gass A: Diffusion-weighted and perfusion MRI demonstrates parenchymal changes in complex partial status epilepticus. Brain 2005;128:1369-1376.

41 Di Bonaventura C, Bonini F, Fattouch J, Mari F, Petrucci S, Carni M, Tinelli E, Pantano P, Bastianello S, Maraviglia B, Manfredi M, Prencipe M, Giallonardo AT: Diffusionweighted magnetic resonance imaging in patients with partial status epilepticus. Epilepsia 2009;50(suppl 1):45-52.
42 Parmar H, Lim SH, Tan NC, Lim CC: Acute symptomatic seizures and hippocampus damage: DWI and MRS findings. Neurology 2006;66:1732-1735.

43 Natsume J, Bernasconi N, Miyauchi M, Naiki M, Yokotsuka T, Sofue A, Bernasconi A: Hippocampal volumes and diffusionweighted image findings in children with prolonged febrile seizures. Acta Neurol Scand Suppl 2007;186:25-28.

$\checkmark 44$ Milligan TA, Zamani A, Bromfield E: Frequency and patterns of MRI abnormalities due to status epilepticus. Seizure 2009;18: 104-108.

-45 Chatzikonstantinou A, Szabo K, Ottomeyer C, Kern R, Hennerici MG: Successive affection of bilateral temporomesial structures in a case of non-paraneoplastic limbic encephalitis demonstrated by serial MRI and FDGPET. J Neurol 2009;256:1753-1755.

46 Thuerl C, Muller K, Laubenberger J, Volk B, Langer M: MR imaging of autopsy-proved paraneoplastic limbic encephalitis in nonHodgkin lymphoma. AJNR Am J Neuroradiol 2003;24:507-511.

47 Urbach H, Soeder BM, Jeub M, Klockgether T, Meyer B, Bien CG: Serial MRI of limbic encephalitis. Neuroradiology 2006;48:380386.

48 Gorniak RJ, Young GS, Wiese DE, Marty FM, Schwartz RB: MR imaging of human herpesvirus-6-associated encephalitis in 4 patients with anterograde amnesia after allogeneic hematopoietic stem-cell transplantation. AJNR Am J Neuroradiol 2006;27: 887-891.

$\checkmark 49$ Noguchi T, Mihara F, Yoshiura T, Togao O, Atsumi K, Matsuura T, Kuroiwa T, Honda H: MR imaging of human herpesvirus-6 encephalopathy after hematopoietic stem cell transplantation in adults. AJNR Am J Neuroradiol 2006;27:2191-2195.

50 Seeley WW, Marty FM, Holmes TM, Upchurch K, Soiffer RJ, Antin JH, Baden LR, Bromfield EB: Post-transplant acute limbic encephalitis: clinical features and relationship to HHV6. Neurology 2007;69:156-165.

-51 Noguchi T, Yoshiura T, Hiwatashi A, Togao O, Yamashita K, Nagao E, Uchino A, Hasuo K, Atsumi K, Matsuura T, Kuroiwa T, Mihara F, Honda H, Kudo S: CT and MRI findings of human herpesvirus 6-associated encephalopathy: comparison with findings of herpes simplex virus encephalitis. AJR Am J Roentgenol 2010;194:754-760.

52 Poon MA, Stuckey S, Storey E: MRI evidence of cerebellar and hippocampal involvement in Creutzfeldt-Jakob disease. Neuroradiology 2001;43:746-749.

53 Siu JCW, Chan CY, Wong YC, Yuen MK: Magnetic resonance imaging findings of Japanese encephalitis. J HK Coll Radiol 2004;7:76-80. 
54 Wijdicks EF, Campeau NG, Miller GM: MR imaging in comatose survivors of cardiac resuscitation. AJNR Am J Neuroradiol 2001; 22:1561-1565.

55 Konaka K, Miyashita K, Naritomi H: Changes in diffusion-weighted magnetic resonance imaging findings in the acute and subacute phases of anoxic encephalopathy. J Stroke Cerebrovasc Dis 2007; 16:82-83.

-56 Mlynash M, Campbell DM, Leproust EM, Fischbein NJ, Bammer R, Eyngorn I, Hsia AW, Moseley M, Wijman CA: Temporal and spatial profile of brain diffusion-weighted MRI after cardiac arrest. Stroke 2010;41: 1665-1672.
Singhal AB, Topcuoglu MA, Koroshetz WJ: Diffusion MRI in three types of anoxic encephalopathy. J Neurol Sci 2002;196:37-40.

58 Finelli PF: Diffusion-weighted MR in hypoglycemic coma. Neurology 2001;57:933.

59 Cho SJ, Minn YK, Kwon KH: Severe hypoglycemia and vulnerability of the brain. Arch Neurol 2006;63:138.

60 Lim CC, Gan R, Chan CL, Tan AW, Khoo JJ, Chia SY, Kao SL, Abisheganaden J, Sitoh YY: Severe hypoglycemia associated with an illegal sexual enhancement product adulterated with glibenclamide: MR imaging findings. Radiology 2009;250:193-201.

-61 Kang EG, Jeon SJ, Choi SS, Song CJ, Yu IK: Diffusion MR imaging of hypoglycemic encephalopathy. AJNR Am J Neuroradiol 2010; 31:559-564.
62 Soares-Fernandes JP, Machado A, Ribeiro M, Ferreira C, Figueiredo J, Rocha JF: Hippocampal involvement in valproate-induced acute hyperammonemic encephalopathy. Arch Neurol 2006;63:1202-1203.

63 Lee HY, Song SY, Lee SH, Lee SY, Kim SH, Ryu SW: Vasogenic edema in striatum following ingestion of glufosinate-containing herbicide. J Clin Neurosci 2009;16:13721373.

-64 Server A, Hovda KE, Nakstad PH, Jacobsen D, Dullerud R, Haakonsen M: Conventional and diffusion-weighted MRI in the evaluation of methanol poisoning. Acta Radiol 2003;44:691-695. 